\title{
PERFORMANCE OPTIMIZATION OF 500MW STEAM TURBINE BY CONDITION MONITORING TECHNIQUE USING VIBRATION ANALYSIS METHOD
}

\author{
Mohammed Fazal Ur Rahman, Prof. Syed Nawazish Mehdi \\ Department of Mechanical Engineering, \\ Singhania University, Pacheri Bari, Rajasthan-333515, India \\ Praveen Kumar B \\ Department of Mechanical Engineering, \\ Talla Padmavathi Collage of Engineering, Warangal, India
}

\begin{abstract}
In this paper, description of vibration analysis method used for condition monitoring of 500MW steam turbine (Kraftwork Union, Germany) has been discussed. The importance and critical role of this technique in predictive maintenance used in thermal power plant is evaluated based on possible type of failures that can be detected at early stage before any unexpected, unscheduled breakdown during operation of steam turbine.

Efforts are being made for most of the steam turbines in power generation thermal plants to run or operate them at Ideal condition by regular technical consultations resulting in continuous generation of power and reasonable increase in operational life span of these turbines. This paper deals with one such effort. In this paper real time condition monitoring of 500MW turbine, which was carried out by them at NTPC-Ramagundum power plant, using vibration analysis, has been discussed without disturbing its operational working condition and the causes for increase in the vibrations and its practical diagnosis by spectrum analysis, Interpretations and recommended steps to be taken to minimize the vibrations.
\end{abstract}

Keywords: Condition Monitoring, Vibration Analysis, Steam Turbine, Optimization, Maintenance.

Cite this Article: Mohammed Fazal Ur Rahman, Prof. Syed Nawazish Mehdi and Praveen Kumar B, Performance Optimization of 500mw Steam Turbine by Condition Monitoring Technique Using Vibration Analysis Method, International Journal of Advanced Research in Engineering and Technology, 10 (5), 2019, pp 1-8.

http://iaeme.com/Home/issue/IJARET?Volume=10\&Issue $=5$ 


\section{INTRODUCTION}

Steam turbines used in power generation plant are very efficient but complex machines resulting in possibility of functional failures. Development of vibration during operation of steam turbine is one among many malfunctions. Mission to provide Electricity for every household, put the pressure on power generation plant for continuous production of power. Vibrations are developed due to impact between stationary and rotating parts [1]. Techniques adopted for maintaining acceptable running conditions of thermal power plant, are called as condition monitoring technique which includes various methods to be adopted based on the mode of degradation. This technique was developed in recent years to such an extent that the working condition data was provided online resulting in early detection of the problem [2]. Condition Monitoring/Condition Based Monitoring is a very strong and effective method of Predictive maintenance by which user can monitor the condition of specific, sensitive and critical areas of equipment in power plant. This experiment, procedure can be carried out on auto bases with the use of instrumentation such as machinery vibration analysis and thermal imaging equipment. In this method, when any equipment is monitored, predefined condition limit of respective equipment exceeded, a signal or output was activated. This generated output, signal sent directly to Condition Monitoring Management System resulting in generation of work order automatically. This method particularly suits to process plants running continuously, where plant failure and downtime can be extremely big loss cost wise. Condition Monitoring mainly deals with continuous analysis of operational equipment under observation and the identification of defects before equipment breakage or failure. Condition Monitoring has mostly been associated with the analysis of rotating and reciprocating equipment. Almost any equipment, either be it mechanical, thermal, electrical or hydraulic, generates characteristic signals or 'signature' during optimal performance. A change in this signal, even if marginal, could be an early warning regarding potential equipment failure [3]. Condition Monitoring leads to undertaking corrective measures only when required rather than at the schedule or routine intervals. Thus resulting in elimination downtime for unnecessary inspections and loss in power generation.

\section{CAUSES OF VIBRATION}

\section{Unbalance}

One of the most common causes of vibration is Unbalance and can be corrected by proper balancing of machine components. Most of the vibrations are in radial direction i.e. horizontal or vertical or axial in the case of overhung and flexible rotors. The amplitude of vibration is proportional to the amount of unbalance present in it. Generally, $1 *$ RPM vibration is greater than $80 \%$ of overall reading. The vertical and horizontal $1 *$ RPM amplitude should be nearly equal, even though it depends on system rigidity in particular direction.

\section{Misalignment}

Misalignment usually causes the bearing to carry higher load than its design specifications which in turn causes bearing damage due to fatigue. It can be the misalignment of the bearing with the shaft, misalignment between bearings or the misalignment between the coupling halves [2]. Sometimes a bent shaft defect also reflects to misalignment. The significant characteristic of vibration will be in both radial and axial direction. Vibration frequencies will usually $1 \mathrm{Xrpm}, 2 \mathrm{Xrpm}$ or $3 \mathrm{Xrpm}$. Axial vibration is the best indicator of misalignment. In general we have three different types of misalignments they are Angular, Parallel and Combination of both angular and parallel 


\section{Mechanical looseness}

When the dominant vibration is at a frequency of $2 \mathrm{Xrpm}$, mechanical looseness can be suspected as a problem. Mechanical looseness of nuts and bolts of the motor-fan assembly supports occurs when the vibration frequency is odd multiples of RPM of the motor. In presence of looseness, even relatively small amount of unbalance or misalignment will result in high vibrations [4]. Looseness itself is not an exciting force, but it allows the exciting frequencies already present to exhibit much higher amplitudes. It contributes to a loss or reduction in normal stiffness of the equipment.

\section{It is characterized by}

- $\quad$ Radial vibration

- $\quad$ XXRPM, 2XRPM peaks are dominant

- A 180 degree phase difference is observed between mating surfaces, which have looseness between them.

\section{Bent shaft}

A rotor bow or bent shaft causes a pre load on the bearings. The Center of mass of a bent shaft can be moved far away from the geometric center to cause some mass unbalance. If the machine passes through a critical speed during start up a diagnostic test can be performed to determine the nature of the bow.

\section{It is characterized by}

- High axial vibrations

- Dominant vibration is normally at 1XRPM if bent shaft center, but at 2XRPM if bent near coupling and the axial phase differences tend towards 180 degrees.

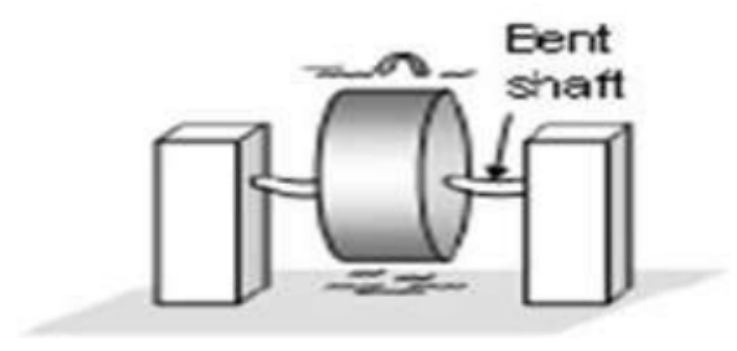

Figure 1 Showing a bent shaft

\section{Resonance}

Natural frequencies exerted by forces as mass, unbalance and its orders amplify vibration. This mechanism is called resonance when it occurs on a structure [4]. The degree of amplification depends on the magnitude of the force and damping as well as the proximity of the forcing frequency to the natural frequency. Either the forcing frequency or a natural frequency must be a change to solve the problem.

\section{Defects in antifriction bearings}

Antifriction bearings that have defects on the rollers or balls usually produce high frequency vibration. These frequencies may be equal to or related to one time the roller or ball rolling frequency. 


\section{Defects of sleeve bearings}

Problems are generally the result of excessive or improper bearing clearance, looseness of habit in the housing and lubrication problems. Bearing faults of the motor assembly is noted when the vibration frequency is 0.43 to 0.47 times the RPM of the motor.

\section{DESCRIPTION OF EQUIPMENT FOR EXPERIMENTAL EXERCISE:}

\section{Turbine}

\section{Specification of main turbine}

Make: KRAFTWERK UNION, WEST GERMANY

Type: Three Cylinder, reheat, Condensing turbine

No of stages: HP 18 Nos. IP 14x2 Nos. LP 6x2 Nos.

Nominal rating: $500 \mathrm{MW}$

Peak Loading: 536.7 MW

Rated Speed: 3000 rpm

Max/Min Speed: 3090/2850 rpm

Speed exclusion range: 400 to $2850 \mathrm{rpm}$.

\section{Transducer}

- The transducer used is an accelerometer type

- It is made by ENTEK (IMI).

- Its sensitivity at $6000 \mathrm{CPM}$ is $9.6 \mathrm{mV} / \mathrm{ms}-2$..

- Model number: 9000A.

- Serial number: P80631.

- Range: $100 \mathrm{mV} / \mathrm{g}$.

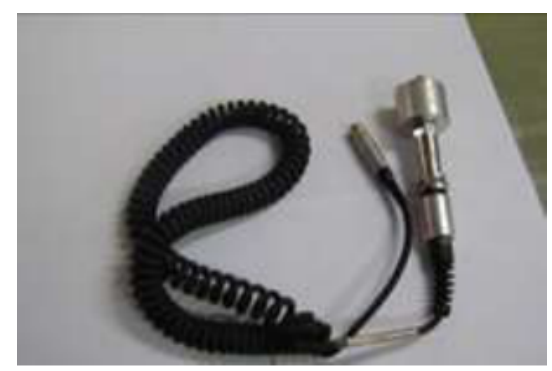

Figure 2 Transducer

\section{Vibration Analyzer}

- Model number: ENPAC 1200A (data collector).

- It is made by ROCKWELL AUTOMATION.

- It is a dual channel vibration analyzer.

- Operating system: Windows CE V 2.x.

- Processor types: Philips PR 31700, DSP processor, Motorola DSP 56303.

- Internal RAM: 16 MB.

- Interface software: EMONITOR Odyssey 


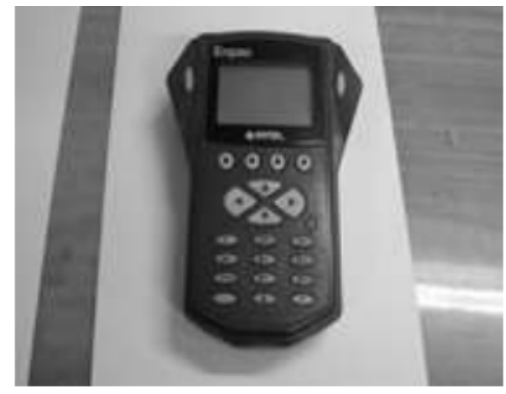

Figure 3 Vibration Analyzer

\section{METHODOLOGY}

Most plants that implement vibration monitoring program begin with a portable data collector and a pre-determined route of data measuring points. Vibration data are gathered and trended. Maintenance actions were then determined based on machinery condition trends [5]. Mostly the new vibration signal information's were reviewed and compared to trended data and no anomalies or exceptions were noted. The methodology technique adopted was Plan-DoCheck-Act. Planning schedule for measuring vibrations of units under operation. Accordingly, data was measured and analyzed based on the standard reading as shown in below table. Based on the outcome on the analysis proper action was taken. Generally the vibration amplitude of turbine simply can be reduced, just by reducing or increasing the quantity of steam flow, the speed, or pressure of steam.

\section{Vibration Limits as Per Standards VDI 2056/59. BS 4675, ISO 2372 for Assessing Turbine Machinery Vibration}

Table 1 Vibration acceptable limits

\begin{tabular}{|c|c|c|c|c|c|c|}
\hline \multirow{3}{*}{$\begin{array}{c}\text { Turbine } \\
\text { Generators }\end{array}$} & \multicolumn{6}{|c|}{ Absolute Bearing Housing Vibration measured by portable equipment's in Horizontal ' $\mathrm{H}$ ' and ' $\mathrm{V}$ ' directions } \\
\hline & \multicolumn{6}{|c|}{ Vibration units - Displacement in Pk-Pk $\mu \mathrm{m} \&$ Velocity in $\mathrm{Pk} \mathrm{mm} / \mathrm{sec}$} \\
\hline & Very good & Good & Fair & Useable & $\begin{array}{l}\text { Still } \\
\text { acceptable }\end{array}$ & $\begin{array}{l}\text { Not } \\
\text { Permissible }\end{array}$ \\
\hline $\begin{array}{l}\text { Stage-II } \\
\text { ( } 3 \text { X } 500 \mathrm{MW})\end{array}$ & $\begin{array}{l}\text { Up to } 18 \mu \mathrm{m} \\
\& \\
2.5 \mathrm{~mm} / \mathrm{sec}\end{array}$ & $\begin{array}{l}18 \mu \mathrm{m} \& \\
2.5 \mathrm{~mm} / \mathrm{sec} \\
\text { to } \\
25 \mu \mathrm{m} \mathrm{\&} \\
4 \mathrm{~mm} / \mathrm{sec}\end{array}$ & $\begin{array}{l}25 \mu \mathrm{m} \& \\
4 \mathrm{~mm} / \mathrm{sec} \text { to } \\
40 \mu \mathrm{m} \mathrm{\&} \\
6.3 \mathrm{~mm} / \mathrm{sec}\end{array}$ & $\begin{array}{l}40 \mu \mathrm{m} \& \\
6.3 \mathrm{~mm} / \mathrm{sec} \\
\text { to } \\
65 \mu \mathrm{m} \mathrm{\&} \\
10 \mathrm{~mm} / \mathrm{sec}\end{array}$ & $\begin{array}{l}65 \mu \mathrm{m} \& \\
10 \mathrm{~mm} / \mathrm{sec} \text { to } \\
100 \mu \mathrm{m} \mathrm{\&} \\
15 \mathrm{~mm} / \mathrm{sec}\end{array}$ & $\begin{array}{l}\text { Above } \\
100 \mu \mathrm{m} \& \\
15 \mathrm{~mm} / \mathrm{sec}\end{array}$ \\
\hline
\end{tabular}

\section{RESULTS AND ANALYSIS}

The data of vibrations displacement and velocity was measured using Vibration analyzer at all six bearings critical points in horizontal, vertical and axial direction for the period of 6 days for analysis. After thorough analysis of obtained data, it has been observed that the amplitude of vibration is not constant at any given time. The displacement and velocity measured at any bearing in horizontal, vertical and axial direction are not same as shown below in table- 2 . This shows the importance of measuring the vibrations magnitude in all three direction of each and every bearing location in order to visualize and understand the behavior of turbine under extreme operational conditions. 
Mohammed Fazal Ur Rahman, Prof. Syed Nawazish Mehdi and Praveen Kumar B

\section{Vibration Data Sheet}

Table 2 Vibration displacement reading at bearings in three directions

\begin{tabular}{|c|c|c|c|c|c|c|c|c|c|c|c|c|c|c|c|c|c|c|}
\hline \multirow{3}{*}{ Location } & \multicolumn{18}{|c|}{ Displacement Peak(microns) } \\
\hline & \multicolumn{3}{|c|}{1} & \multicolumn{3}{|c|}{2} & \multicolumn{3}{|c|}{3} & \multicolumn{3}{|c|}{4} & \multicolumn{3}{|c|}{5} & \multicolumn{3}{|c|}{6} \\
\hline & $\mathbf{H}$ & $\mathbf{V}$ & $\mathbf{A}$ & $\mathbf{H}$ & $\mathbf{V}$ & $\mathbf{A}$ & $\mathbf{H}$ & $\mathbf{V}$ & $\mathbf{A}$ & $\mathbf{H}$ & $\mathbf{V}$ & $\mathbf{A}$ & $\mathbf{H}$ & $\mathbf{V}$ & $\mathbf{A}$ & $\mathbf{H}$ & $\mathbf{V}$ & $\mathbf{A}$ \\
\hline Bearing -1 & 5.0 & 4.0 & 5.0 & 26.0 & 12.0 & 22.0 & 26.0 & 12.0 & 22.0 & 28.0 & 25.0 & 35.0 & 30.0 & 15.0 & 20.0 & 29.0 & 16.0 & 8.0 \\
\hline Bearing -2 & 5.0 & 12.0 & 5.0 & 10.0 & 8.0 & 10.0 & 10.0 & 8.0 & 10.0 & 15.0 & 15.0 & 10.0 & 14.0 & 14.0 & 15.0 & 14.0 & 12.0 & 15.0 \\
\hline Bearing -3 & 7.0 & 6.0 & 8.0 & 8.0 & 12.0 & 18.0 & 8.0 & 12.0 & 18.0 & 11.0 & 46.0 & 41.0 & 20.0 & 10.0 & 30.0 & 19.0 & 8.0 & 22.0 \\
\hline Bearing -4 & 6.0 & 5.0 & 7.0 & 20.0 & 8.0 & 12.0 & 20.0 & 8.0 & 12.0 & 46.0 & 19.0 & 53.0 & 37.0 & 18.0 & 37.0 & 42.0 & 16.0 & 57.0 \\
\hline Bearing -5 & 8.0 & 10.0 & 6.0 & 20.0 & 27.0 & 13.0 & 20.0 & 27.0 & 13.0 & 8.0 & 8.0 & 7.0 & 12.0 & 8.0 & 8.0 & 13.0 & 8.0 & 7.0 \\
\hline Bearing -6 & 4.0 & 5.0 & 4.0 & 14.0 & 9.0 & 8.0 & 14.0 & 9.0 & 8.0 & 8.0 & 11.0 & 5.0 & 10.0 & 12.0 & 6.0 & 11.0 & 13.0 & 6.0 \\
\hline
\end{tabular}

Table 3 Vibration Velocity reading at bearings in three directions

\begin{tabular}{|c|c|c|c|c|c|c|c|c|c|c|c|c|c|c|c|c|c|c|}
\hline \multirow{3}{*}{ Location } & \multicolumn{18}{|c|}{ Velocity $(\mathbf{m m} / \mathbf{s})$} \\
\hline & \multicolumn{3}{|c|}{1} & \multicolumn{3}{|c|}{2} & \multicolumn{3}{|c|}{3} & \multicolumn{3}{|c|}{4} & \multicolumn{3}{|c|}{5} & \multicolumn{3}{|c|}{6} \\
\hline & $\mathbf{H}$ & $\mathbf{V}$ & $\mathbf{A}$ & $\mathbf{H}$ & $\mathbf{V}$ & $\mathbf{A}$ & $\mathbf{H}$ & $\mathbf{V}$ & $\mathbf{A}$ & $\mathbf{H}$ & $\mathbf{V}$ & $\mathbf{A}$ & $\mathbf{H}$ & $\mathbf{V}$ & $\mathbf{A}$ & $\mathbf{H}$ & $\mathbf{V}$ & $\mathbf{A}$ \\
\hline Bearing -1 & 4.0 & 1.8 & 2.4 & 4.8 & 2.3 & 3.9 & 4.8 & 3.0 & 3.9 & 5.0 & 4.2 & 5.6 & 5.3 & 2.0 & 4.2 & 5.0 & 2.9 & 1.8 \\
\hline Bearing -2 & 1.6 & 5.1 & 1.6 & 1.4 & 1.3 & 1.2 & 1.4 & 1.3 & 1.2 & 3.4 & 2.0 & 1.2 & 2.2 & 1.6 & 2.6 & 2.1 & 1.6 & 2.2 \\
\hline Bearing -3 & 1.4 & 2.0 & 2.8 & 1.5 & 2.0 & 3.0 & 1.5 & 2.0 & 3.0 & 2.3 & 2.3 & 4.6 & 2.4 & 0.2 & 3.4 & 3.0 & 2.8 & 3.3 \\
\hline Bearing -4 & 7.9 & 2.6 & 3.2 & 5.8 & 2.2 & 2.6 & 5.8 & 2.2 & 2.6 & 8.9 & 3.9 & 8.4 & 7.4 & 3.1 & 6.0 & 8.3 & 3.0 & 9.5 \\
\hline Bearing - 5 & 2.8 & 3.7 & 2.8 & 3.5 & 4.7 & 2.8 & 3.5 & 4.7 & 2.8 & 1.6 & 1.9 & 1.7 & 1.8 & 2.0 & 2.0 & 2.4 & 2.1 & 1.6 \\
\hline Bearing -6 & 1.3 & 2.4 & 2.4 & 2.3 & 2.5 & 2.2 & 2.3 & 2.5 & 2.2 & 1.6 & 2.2 & 0.8 & 1.6 & 2.4 & 0.8 & 2.2 & 2.9 & 1.2 \\
\hline
\end{tabular}

In Fig.4, shows the graphical representation of relative behavior of vibration velocities of bearings in horizontal direction over a period of time. It has been observed that there was sudden increase in vibrations at sixth bearing on fourth day. After analysis, the problem leading for this condition was found to be because of Imbalance, which was solved by adding dead weights gradually by 30-30 rule method in opposite direction, resulting in bringing down the vibration magnitude within tolerance limit. 
Performance Optimization of 500mw Steam Turbine by Condition Monitoring Technique Using Vibration Analysis Method

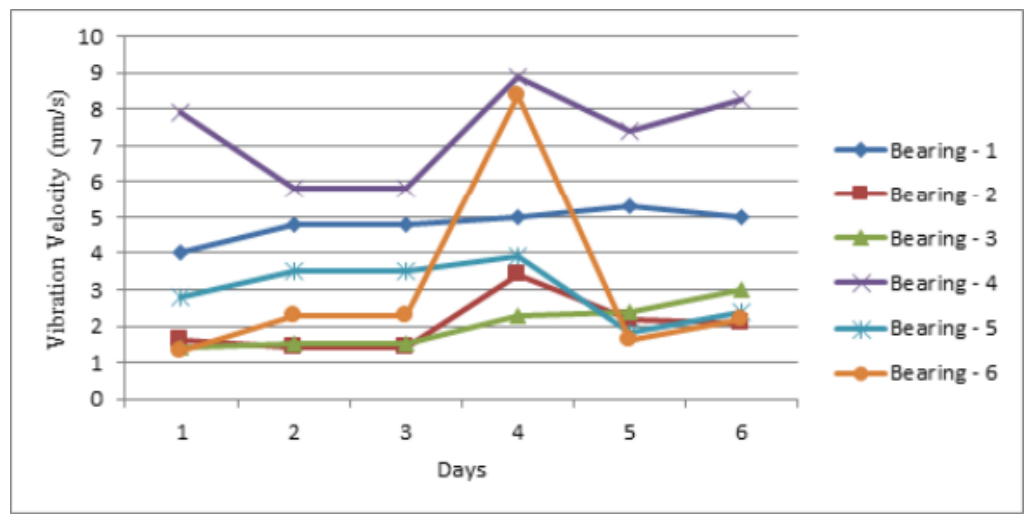

Figure 4 Peak Vibration velocity $(\mathrm{mm} / \mathrm{s})$ vs. Day in Horizontal Direction

In Fig.5, fifth bearing was showing high vibration velocity for three consecutive days in vertical direction because of Misalignment which was solved by shimming mounting pads and the vibration was brought done as shown in the below graph. Similarly on first day high vibrations was observed at second bearing and the reason for such behavior was found to be resonance which was solved by altering the pressure of steam entering the turbine.

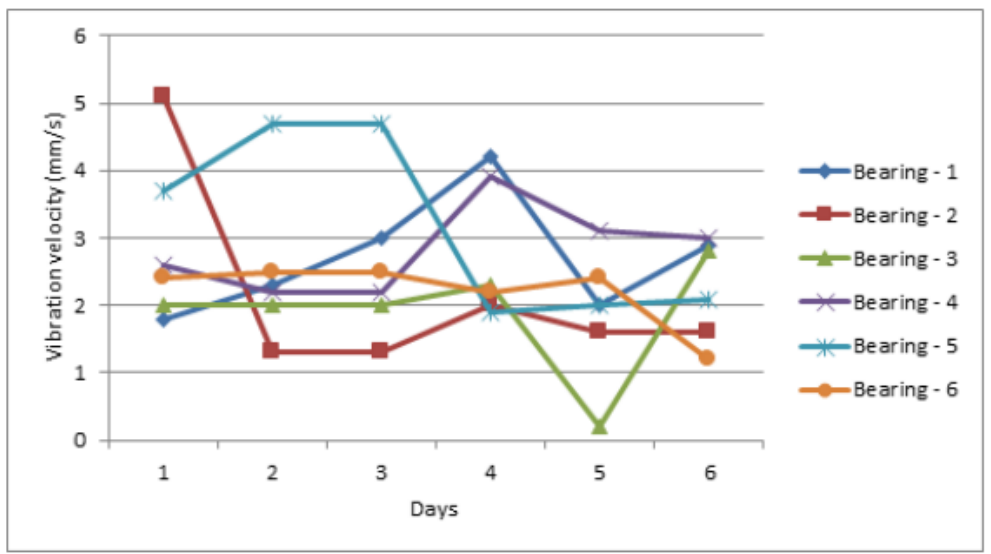

Figure 5 Peak Vibration velocity $(\mathrm{mm} / \mathrm{s})$ vs. Day in Vertical Direction

In axial direction, the magnitude of vibrations at fourth and first bearing were high as shown in Fig.6. Necessary action was recommended before vibration go beyond tolerance limits. Fourth bearing was showing sudden increase in the vibration velocity on fourth day in axial direction. Problem found after analysis was Mechanical looseness which was solved by increasing the rigidity of Equipment.

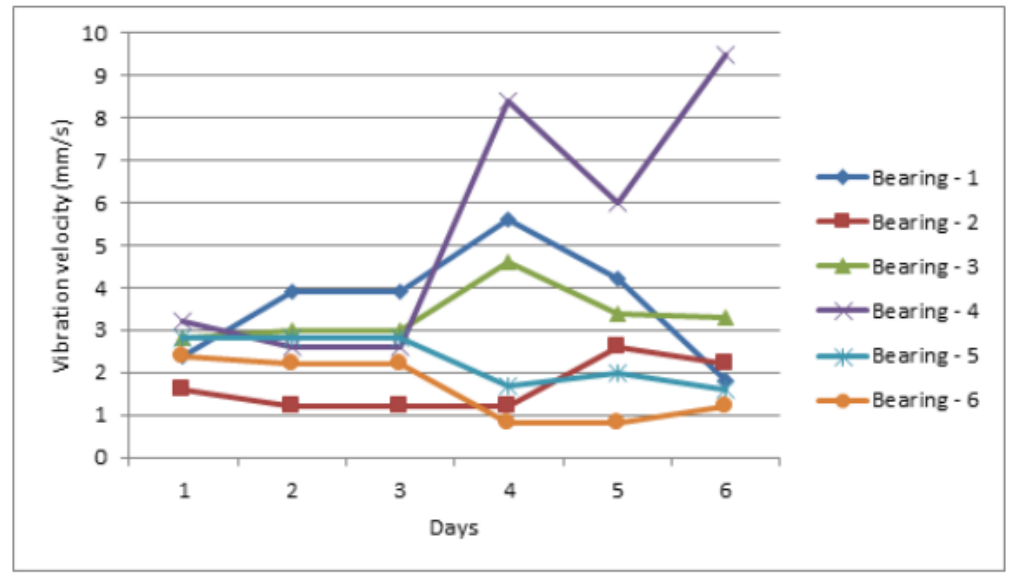

Figure 5 Peak Vibration velocity $(\mathrm{mm} / \mathrm{s})$ vs. Day in Axial Direction 


\section{CONCLUSIONS}

Vibration analysis method for condition monitoring technique is very effective in analyzing the working condition of steam turbines. The magnitudes of vibration measured by vibrator analyzer at each bearing in all three directions are very accurate and reliable. Above all problems aroused were detected and solved by carry out appropriate action at early state. This was possible because of vibration analysis. If not, there were many instances during the operation of turbine where increasing vibrations developed goes unchecked, would lead to catastrophic loss for functionality and safely of the whole power plant. This shows significance, cruciality and importance of this method.

But still, this is not only the one method on which condition monitoring is depended, simultaneously various other methods are also adopted on its individual basis. This shows there is still lot of scope in the improvisation and optimization in the integration of various methods of condition monitoring techniques of turbines.

\section{REFERENCES}

[1] Vibration Analysis Handbook by J. J. Taylor; Vibration Consultants, pp. 152-154.

[2] Condition Monitoring of Steam Turbines by Performance Analysis by Ray Beebe, JQME, Vol.9, pp.100-113, 2003.

[3] Mani Kant and Dr. Prabhat Kumar Sinha, Study \& Vibration Analysis of gradual decrease Beam by FEM, International Journal of Mechanical Engineering and Technology 9(1), 2018. pp. 431-444.

[4] Vibration Analysis Process and Its Implementation by K. L. Mitra, R.J. Sing Sadhana, Vol.13, Part.3, pp. 17-28, 2013.

[5] Kishor B. Waghulde, Dr. Bimlesh Kumar, Vibration Analysis and Control of Piezoelectric Smart Structures by Feedback Controller along- With Spectra plus Software .International Journal of Mechanical Engineering and Technology (IJMET).Volume:3, Issue: 2, 2012, Pages: 783-795.

[6] Free Vibration Analysis of Passenger Boat, Muhamm Ed Shahid Ali and Dr.C.G Nandakumar, International Journal of Design and Manufacturing Technology (IJDMT), Volume 5, Issue 3, September - December (2014), pp. 01-07

[7] Review on Vibration Analysis with Digital Image Processing, Mane Sameer S and Dr. Gawade S.S, International Journal of Advanced Research in Engineering and Technology (IJARET) Volume 4, Issue 3, April 2013, pp. 62-67

[8] Jayant S. Karajagikar and Dr. Bhagwan U. Sonawane. Statistics Based Acceptance Criteria for Vibration Analysis and Maintenance Decision Making on Gearbox Application Test Rig. International Journal of Mechanical Engineering and Technology, 8(6), 2017, pp. 525-529.

[9] Mechanical Vibrations, McGraw-Hill by William W. Seto, 2nd edition, Pearson Education, 5th edition, pp. 2-50, 1995.

[10] Shailesh Pancholi, Meet N. Patel, S. P. Nikhil Kumar and Narendiranath Babu T, Stress and Vibration Analysis on Two-Stage Reduction Gearbox Using Finite Elements Method, International Journal of Mechanical Engineering and Technology, 9(8), 2018, pp. 1111-1125.

[11] Steam Turbine Condition Monitoring by Vibration Analysis by H. A. Searle, PTSAST, pp. 100-108, 2007. 